\title{
Controlled Synthesis and Growth of Perfect Platinum Nanocubes Using a Pair of Low-Resistivity Fastened Silicon Wafers and Their Electrocatalytic Properties
}

\author{
Jitendra N. Tiwari ${ }^{1,2}(\varangle)$, Rajanish N. Tiwari ${ }^{1}$, and Kunlin Lin $^{3}$ \\ ${ }^{1}$ Department of Materials Science and Engineering, National Chiao Tung University, 1001 Ta Hsueh Road, Hsinchu, Taiwan 30050,China \\ ${ }^{2}$ Center for Superfunctional Materials, Department of Chemistry, Pohang University of Science and Technology, San 31, Hyojadong, Namgu, \\ Pohang 790-784, South Korea \\ ${ }^{3}$ National Nano Device Laboratories, No. 26, Prosperity Road I, Science-Based Industrial Park, Hsinchu, Taiwan 30078, China \\ Received: 3 December 2010 / Revised: 7 January 2011 / Accepted: 18 January 2011 \\ (C) Tsinghua University Press and Springer-Verlag Berlin Heidelberg 2011
}

\begin{abstract}
Perfect platinum $(\mathrm{Pt})$ nanocubes with high density have been synthesized by controlled reduction of hexachloroplatinic acid in the presence of $\mathrm{H}_{2} \mathrm{SO}_{4}$ and $\mathrm{HCl}$, employing a pair of low-resistivity fastened silicon (FS) wafers at room temperature. The presence of the additive charges (induced by prior etching of the silicon surface with $\mathrm{HF}$ to remove any $\mathrm{SiO}_{2}$ layer) between the interfaces of the FS surface results in a high charge density and facilitates fast deposition of Pt nanoparticles via electroless plating. The charge density, stirring time, and homogeneity of the aqueous solution influenced the geometrical shapes of the Pt nanoparticles. The parameters were finely tuned in order to control the nucleation and growth rates and obtain perfect Pt nanocubes. The perfect Pt nanocubes were single crystalline with exposed $\{100\}$ facets. Per equivalent Pt surface areas, the perfect $\mathrm{Pt}$ nanocubes showed enhanced catalytic activity relative to truncated $\mathrm{Pt}$ nanocubes or spherical $\mathrm{Pt}$ nanoparticles for the electrooxidation of liquid feed fuels such as methanol and ethanol. Moreover, there a strong correlation was observed between the optical, electrical, thermal, magnetic, and catalytic properties of the perfect Pt nanocubes which should lead to a variety of technological applications of these materials.
\end{abstract}

\section{KEYWORDS}

Fastened silicon wafers, charge density, Pt nanocubes, catalytic activity, liquid feed fuel cells

\section{Introduction}

Currently, the synthesis and growth mechanism of the shape-controlled platinum $(\mathrm{Pt})$ nanostructures is of fundamental interest, and also potentially very useful because of their wide range of applications in photocatalysis [1], hydrogen production [2], liquid feed fuel cell catalysis [3-6], surface enhanced Raman scattering [7], fine chemical synthesis [8], reduction of pollutant gases emitted from automobiles, the synthesis of nitric acid, and oil cracking reactions [9]. The synthesis of metal nanoparticles with well-controlled sizes, facets, and shapes can also effectively influence their optical, electrical, thermal, magnetic, chemical, and catalytic properties [9-11]. Thus, different Pt nanoparticle shapes have been synthesized in high

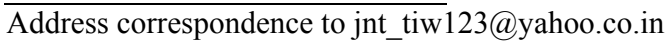


density, including nanocubes [12-14], nanorods [15], nanotubes, [16] and dendritic nanoparticles [16-18]. Among these shapes, well-controlled Pt nanocubes with high density are particularly interesting due to their high catalytic activity in different catalytic reactions. For instance, $\mathrm{Pt}$ nanocubes with exposed $\{100\}$ facets are more active and selective than conventional NO reduction catalysts [19]. Furthermore, the oxidation of ammonia almost exclusively takes place on $\mathrm{Pt}\{100\}$ facets [20].

Many previous studies have also shown that the presence of $\mathrm{Pt}\{100\}$ facets enhances the catalytic activity for hydrogen oxidation reactions and the oxygen reduction reaction [21,22]. In the last few years, several chemical methods have been developed for the synthesis of Pt nanocubes [23, 24], but most of these methods are either tedious or difficult to control, making it exceedingly challenging to synthesize such $\mathrm{Pt}$ nanocubes. In addition, the fundamental factors dictating the formation of shape-controlled nanoparticles have not been elucidated to date.

In this work, we describe a new, simple, and efficient method for the synthesis and growth of well-dispersed perfect Pt nanocubes, employing a pair of low-resistivity fastened silicon (FS) wafers at room temperature in the absence of surfactant, reducing agents, additives, or capping materials. In addition, we found that the morphology and dimensions of the Pt nanocubes were greatly influenced by the homogeneity of the aqueous solutions, the dipping time, stirring time, and charge density of the substrate. Moreover, the perfect Pt nanocubes show excellent electrocatalytic activity and good stability in methanol and ethanol oxidation.

\section{Experimental}

\subsection{Synthesis of $\mathrm{Pt}$ nanostructures}

Our synthesis of Pt nanoparticles is based on Faraday's first law of electrolysis, which states that the mass of a substance altered at an electrode during electrolysis is directly proportional to the quantity of charge transferred at that electrode. The negative potential and the electrostatic force of interaction developed between two silicon wafers is higher than that of a single silicon wafer, resulting in fast deposition of $\mathrm{Pt}$ nanoparticles on the pair of fastened silicon (FS) wafers. The synthesis process of the $\mathrm{Pt}$ nanocubes and a possible mechanism of reduction $\mathrm{Pt}^{4+}$ ions to metallic Pt are illustrated in Figs. 1 and 2, respectively. More details are given in the Electronic Supplementary Material (ESM). In brief, a pair of Si wafers was dipped in a $10 \mathrm{wt} . \% \mathrm{HF}$ aqueous solution for $5 \mathrm{~min}$ in order to remove any native $\mathrm{SiO}_{2}$ layer from the silicon samples. Subsequently, the silicon wafers were fastened together with the gap between them being $\sim 1 \mu \mathrm{m}$, as measured by an optical microscope. Dipping the pair of fastened wafers in an unstirred aqueous solution of $2 \mathrm{~mol} / \mathrm{L} \mathrm{H}_{2} \mathrm{PtCl}_{6}+1 \mathrm{~mol} / \mathrm{L} \mathrm{H}_{2} \mathrm{SO}_{4}$ which had been previously vigorously stirrred for either $3 \mathrm{~h}$ or $5 \mathrm{~h}$, led

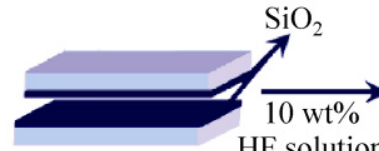

(a)

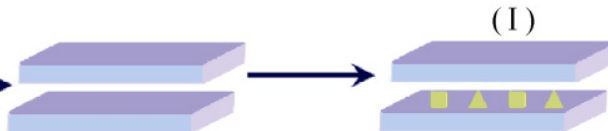

(b) 5 -Hour $\downarrow$ stirring

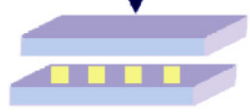

(d)

Truncated tetrahedron

Truncated cubes

Perfect cubes

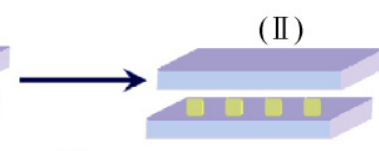

(c)

Figure 1 Schematic illustration of the synthesis procedure for Pt nanocubes: (a) the Si-wafer is cut into $1.5 \times 2 \mathrm{~cm}^{2}$ samples; (b) dipped into HF aqueous solution for $5 \mathrm{~min}$ in order to remove any native oxide layer; and (c) then the polished side of two identical cut pieces of the Si-wafer were fastened together and dipped into $2 \mathrm{~mol} / \mathrm{L} \mathrm{H}_{2} \mathrm{PtCl}_{6}+1 \mathrm{~mol} / \mathrm{L} \mathrm{H}_{2} \mathrm{SO}_{4}$ aqueous solutions, (after stirring for ( I) $3 \mathrm{~h}$ and (II) $5 \mathrm{~h}$ ) to form the truncated (cubes + tetrahedra) and truncated cubes respectively; (d) perfect Pt nanocubes were produced by adding $1 \mathrm{~mol} / \mathrm{L} \mathrm{HCl}$ to the $2 \mathrm{~mol} / \mathrm{L} \mathrm{H}_{2} \mathrm{PtCl}_{6}+1 \mathrm{~mol} / \mathrm{L} \mathrm{H}_{2} \mathrm{SO}_{4}$ aqueous solution (with vigorous stirring for $5 \mathrm{~h}$ ) subsequently immersing the pair of fastened silicon wafers 


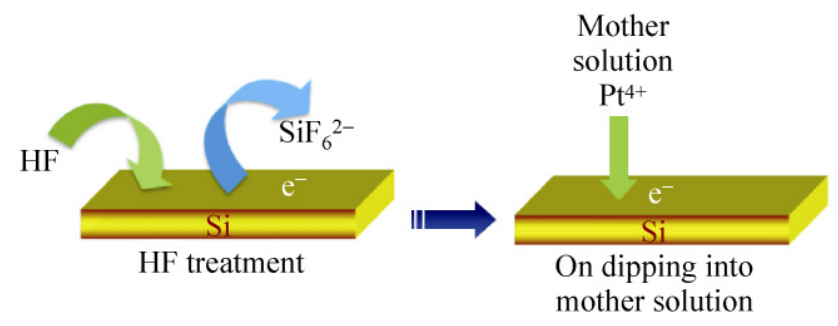

Figure 2 Systematic representation of Pt deposition on an HFetched Si substrate

to the formation of truncated Pt (cubes + tetrahedra) or truncated Pt nanocubes, respectively. The perfect Pt nanocubes were synthesized by dipping a pair of fastened silicon wafers in an unstirred aqueous solution of $1 \mathrm{~mol} / \mathrm{L} \mathrm{HCl}+2 \mathrm{~mol} / \mathrm{L} \mathrm{H}_{2} \mathrm{PtCl}_{6}+1 \mathrm{~mol} / \mathrm{L} \mathrm{H}_{2} \mathrm{SO}_{4}$ which had been previously vigorously stirred for $5 \mathrm{~h}$ at room temperature. The nucleation and growth in the synthesis of the Pt nanocubes were affected by both physical and chemical conditions. For example, the stirring time used to prepare the dipping solution and the dipping time of the FS wafers exert a physical effect, while the concentrations of $\mathrm{H}_{2} \mathrm{PtCl}_{6}, \mathrm{H}_{2} \mathrm{SO}_{4}$, and $\mathrm{HCl}$ exert a chemical effect. For the synthesis of perfect $\mathrm{Pt}$ nanocubes, we optimized the concentrations of $\mathrm{HCl}$, $\mathrm{H}_{2} \mathrm{PtCl}_{6}, \mathrm{H}_{2} \mathrm{SO}_{4}$, and the stirring time of the aqueous precursor solution.

\subsection{Etching of adsorbed $\mathrm{Cl}^{-}$ions}

$\mathrm{Cl}^{-}$ions were weakly adsorbed on the Pt nanostructures in aqueous solution and were easily removed by washing with deionized water.

\subsection{Electron microscopy}

Surface morphologies of the truncated Pt (cubes + tetrahedra), the truncated $\mathrm{Pt}$ nanocubes, the truncated $\mathrm{Pt}$ nanorods and the perfect Pt nanocubes were characterized by a JEOL JSM-6700F high-resolution field emission scanning electron microscope (SEM). Transmission electron microscope (TEM) micrographs were obtained using a JEOL JEM-3000F TEM operated at $200 \mathrm{kV}$. The TEM specimen was prepared by mechanically scratching the nanocube thin film using dissecting forceps in the presence of a small drop of ethanol. The scratched specimen was put onto a holey copper grid and dried in air at room temperature.

\section{Results and discussion}

\subsection{Characterization of samples}

SEM was carried out to investigate the surface morphology of the synthesized $\mathrm{Pt}$ nanostructures on the surface of FS wafers. Figures 3(a)-3(c), show plane-view SEM images of the truncated Pt (cubes + tetrahedra), obtained with dipping times of $10 \mathrm{~min}$, $13 \mathrm{~min}$, and $15 \mathrm{~min}$ respectively, in an aqueous solution of $2 \mathrm{~mol} / \mathrm{L} \mathrm{H}_{2} \mathrm{PtCl}_{6}+1 \mathrm{~mol} / \mathrm{L} \mathrm{H}_{2} \mathrm{SO}_{4}$ at room temperature which had previously been stirred for $3 \mathrm{~h}$. The size of the Pt nanostructures increased as the dipping time of the FS wafers was increased. Figure 3(c) clearly indicates that after dipping in the aqueous solution for $15 \mathrm{~min}$, the product was mainly composed
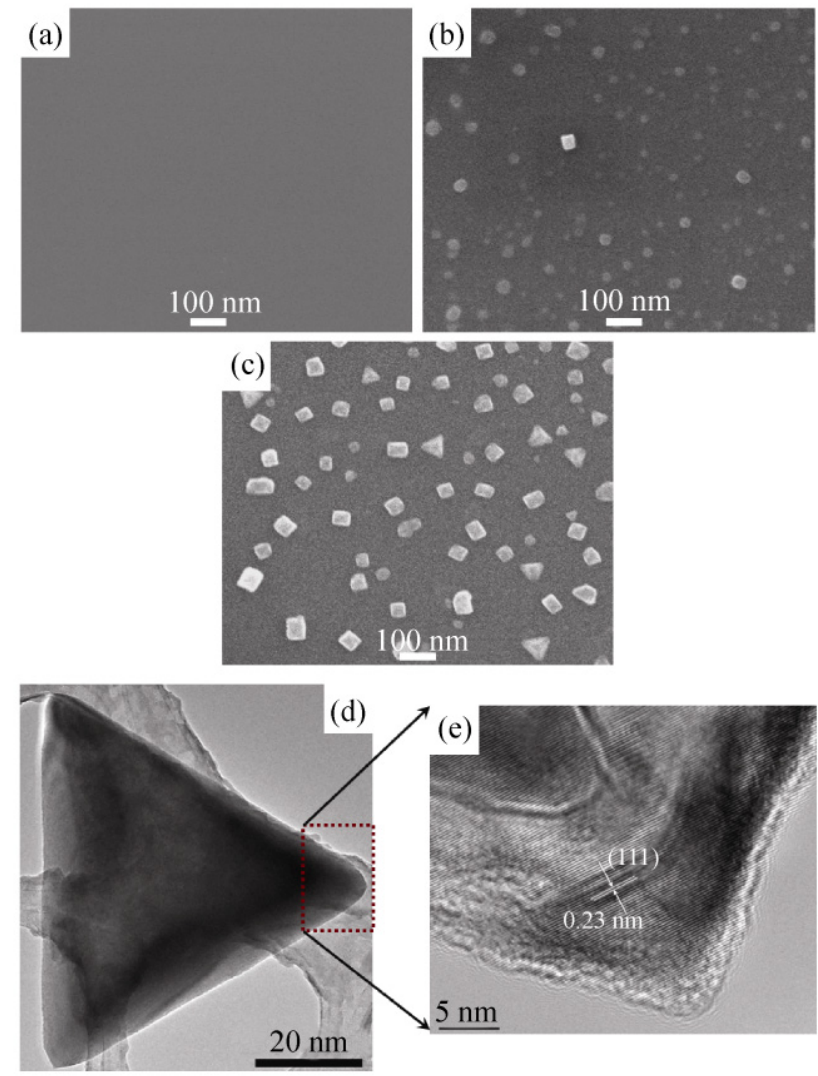

Figure 3 SEM images of truncated $\mathrm{Pt}$ (cubes + tetrahedra) deposited on the FS substrates at room temperature for (a) 10 , (b) 13, and (c) $15 \mathrm{~min}$ (after stirring the solution for $3 \mathrm{~h}$ ); (d) lowmagnification TEM image of an individual truncated Pt tetrahedron; (e) high-resolution TEM lattice image of the region enclosed in the square in (d). The $d$-spacing between the fringes is $\sim 0.23 \mathrm{~nm}$, which is characteristic of the $\{111\}$ planes of $\mathrm{Pt}$ 
of truncated $\mathrm{Pt}$ nanocubes with some truncated $\mathrm{Pt}$ tetrahedra. The morphology of the truncated $\mathrm{Pt}$ tetrahedral nanostructures was further investigated by TEM and high-resolution transmission electron microscopy (HRTEM). Figure 3(d) shows a bright field TEM image of an individual truncated $\mathrm{Pt}$ tetrahedron nanostructure. It can be clearly seen that the size of the truncated $\mathrm{Pt}$ tetrahedron is smaller than $\sim 80 \mathrm{~nm}$. Figure 3(e) shows a HRTEM image taken from a corner of the truncated $\mathrm{Pt}$ tetrahedron. The measured atomic spacing from the HRTEM image (Fig. 3(e)) is $\sim 0.23 \mathrm{~nm}$, which corresponds to the $\{111\}$ lattice planes of $\mathrm{Pt}$, indicating that the truncated $\mathrm{Pt}$ tetrahedron grew along the $\{111\}$ direction.

In addition, to investigate the influence of the stirring time of the precursor solution on the shape of the $\mathrm{Pt}$ nanostructures, the solution of $2 \mathrm{~mol} / \mathrm{L} \mathrm{H}_{2} \mathrm{PtCl}_{6}+$ $1 \mathrm{~mol} / \mathrm{L} \mathrm{H}_{2} \mathrm{SO}_{4}$ was stirred for $5 \mathrm{~h}$ before use. Figures 4(a)-4(c) display plane-view SEM images of the deposited truncated $\mathrm{Pt}$ nanocubes obtained by dipping the FS wafers in the solution for 13, 15, and $20 \mathrm{~min}$, respectively. For dipping times of 13 or $15 \mathrm{~min}$, the vast majority ( $\sim 98 \%$ ) of the resulting Pt nanostructures were truncated nanocubes (Figs. 4(a) and 4(b)). In the case of a longer dipping time of $20 \mathrm{~min}$, the resulting nanostructures consisted of a mixture of well dispersed truncated Pt nanocubes and Pt nanorods (Fig. 4(c)). The morphological evolution of the nanocubes suggests that the larger nanocubes or nanorods originated because of surface energy minimization and Ostwald ripening (see Fig. S-1 in the ESM): when the precursor solution was stirred for $3 \mathrm{~h}$, a large number of truncated Pt tetrahedra with some truncated Pt nanocubes were formed (Fig. 3(c)), whilst when the stirring time was extended to $5 \mathrm{~h}$, only the Pt nanocubes were observed (Fig. 4(b)). This might be partly due to the homogeneity of the aqueous solution being controlled by the stirring time. Figures $4(\mathrm{~d})$ and 4(e) show representative TEM and HRTEM images of an individual truncated $\mathrm{Pt}$ nanocube. From the TEM image, the size of the truncated $\mathrm{Pt}$ nanocube was estimated to be $\sim 80 \mathrm{~nm}$. The HRTEM image in Fig. 4(e) (of the same nanocube as in Fig. 4(d)) shows continuous lattice fringes with a lattice spacing of $\sim 0.20 \mathrm{~nm}$, which corresponds to the $\{100\}$ planes of Pt. Furthermore, the selected area electron diffraction (SAED) pattern
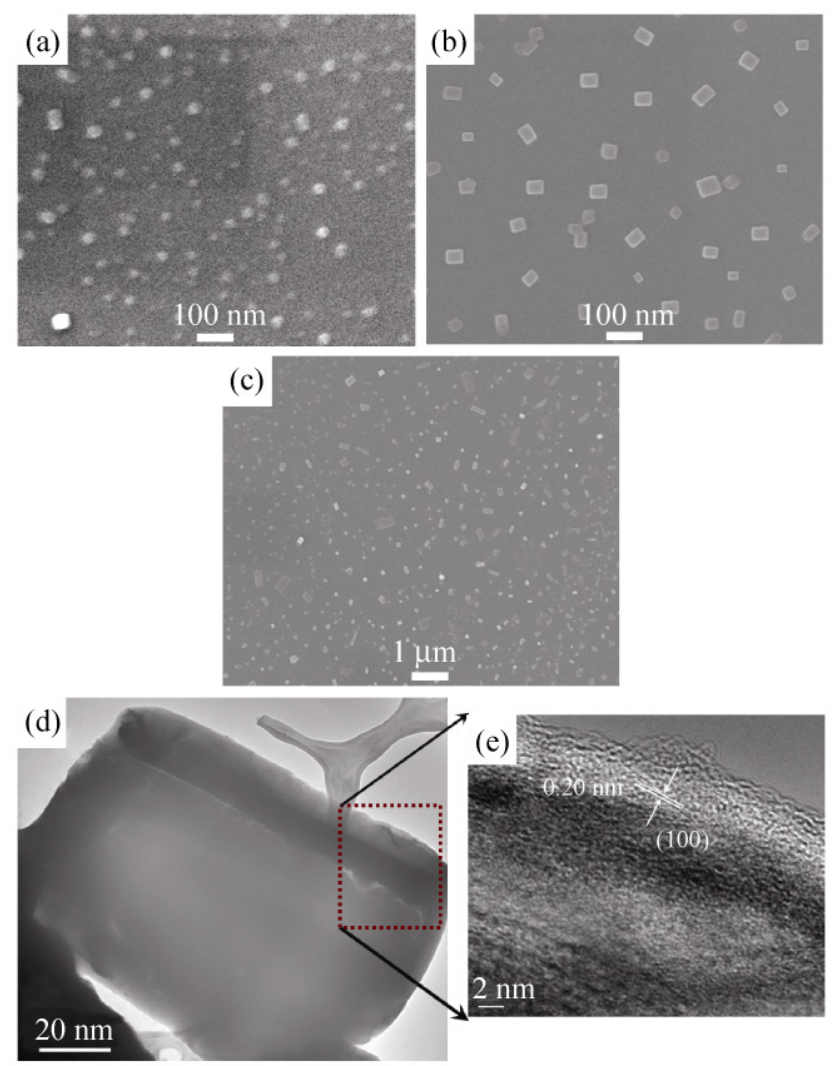

Figure 4 SEM images of truncated Pt nanocubes deposited on the FS substrates at room temperature for (a) 13, (b) 15, and (c) $20 \mathrm{~min}$ (after stirring the solution for $5 \mathrm{~h}$ ); (d) low-magnification TEM image of an individual truncated Pt nanocube; (e) high-resolution TEM lattice image of the region enclosed in the square in (d). The $d$-spacing between the fringes is $\sim 0.20 \mathrm{~nm}$, which is characteristic of the $\{100\}$ planes of $\mathrm{Pt}$

obtained by directing the electron beam perpendicular to the individual truncated Pt nanocube (Fig. S-2 in the ESM) confirmed that the truncated Pt nanocube was a single crystal. Figure S-3(a) (in the ESM) shows the corresponding particle size distribution histogram of the as-synthesized truncated Pt nanocubes shown in Fig. 4(b). It was found that the size of the truncated Pt nanocubes ranged from $10 \mathrm{~nm}$ to $50 \mathrm{~nm}$, with an average size of $15 \mathrm{~nm}$.

However, perfect $\mathrm{Pt}$ nanocubes could be obtained by adding $1 \mathrm{~mol} / \mathrm{L} \mathrm{HCl}$ to the mixture of $2 \mathrm{~mol} / \mathrm{L}$ $\mathrm{H}_{2} \mathrm{PtCl}_{6}+1 \mathrm{~mol} / \mathrm{L} \mathrm{H}_{2} \mathrm{SO}_{4}$ aqueous solution. To explore the growth mechanism of the $\mathrm{Pt}$ nanocubes, timedependent experiments were again carried out at room temperature. A series of SEM images taken at different dipping times $(t)$ are presented in (Figs. 5(a)-5(c)). As shown in Fig. 5(a), at $t=10 \mathrm{~min}$, the Pt nanocubes 
were very hard to observe in the SEM image. When $t=13 \mathrm{~min}$, the Pt nanocubes had started to develop on the both side of the FS sample (Fig. 5(b)). At $t=$ $15 \mathrm{~min}$, the Pt nanocubes had started to grow all over the substrate (Fig. 5(c)).

X-ray photoelectron spectroscopy (XPS) data of the perfect $\mathrm{Pt}$ nanocubes were also recorded. Figure S-4 (in the ESM) shows an XPS survey analysis of a Pt nanocube deposited on a FS sample. Two distinct $\mathrm{Pt}$ $\left(4 \mathrm{f}_{7 / 2}\right)$ and $\mathrm{Pt}\left(4 \mathrm{f}_{5 / 2}\right)$ peaks at 71.0 and $74.2 \mathrm{eV}$, respectively, were clearly observed (Fig. S-5 in the ESM). These are typical values for zerovalent Pt [25]. Furthermore, no obvious shoulders at higher binding energies, characteristic of $\mathrm{Pt}^{2+}$ and $\mathrm{Pt}^{4+}$, were found, and no peak from chlorine in the Pt precursor was detected by XPS (Fig. S-6 in the ESM). From XPS analysis, we can
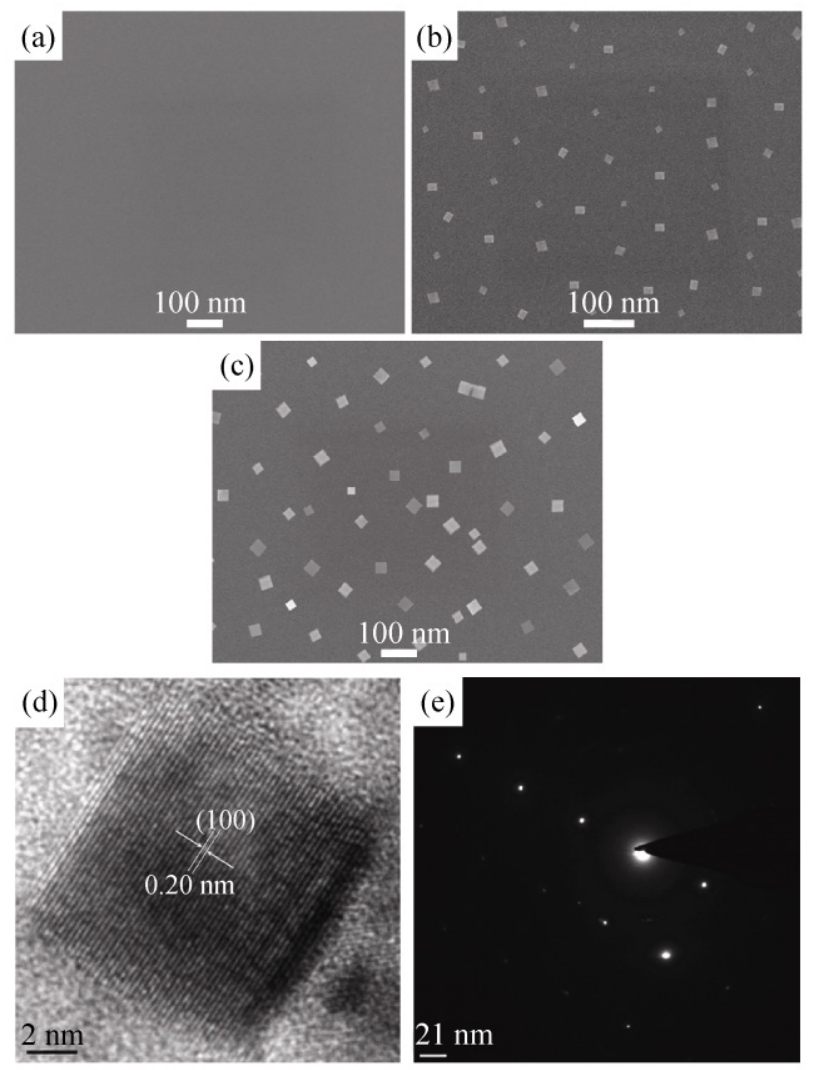

Figure 5 SEM images of perfect Pt nanocubes deposited on the FS substrates at room temperature for (a) 10, (b) 13, and (c) $15 \mathrm{~min}$ (after stirring the solution for $5 \mathrm{~h}$ ); (d) high-resolution TEM image of an individual perfect Pt nanocube. The $d$-spacing between the fringes is $\sim 0.20 \mathrm{~nm}$, which is characteristic of the $\{100\}$ planes of Pt; (e) the corresponding SAED pattern, showing the single crystal structure of the perfect $\mathrm{Pt}$ nanocubes therefore conclude that the perfect $\mathrm{Pt}$ nanocubes were composed of metallic Pt.

The morphology of the perfect Pt nanocubes was further investigated by HRTEM. Figure 5(d) shows an HRTEM image of an individual $\mathrm{Pt}$ nanocube. From the TEM image, it is clear that the Pt nanocubes have a perfect regular shape, with a size of $\sim 10 \mathrm{~nm}$. Figure S-3(b) (in the ESM) shows the corresponding particle size distribution histogram of the as-prepared perfect Pt nanocubes shown in Fig. 5(b). The size of the perfect $\mathrm{Pt}$ nanocubes ranged from $10 \mathrm{~nm}$ to $40 \mathrm{~nm}$, with an average size of $14 \mathrm{~nm}$. Figure 5(e) displays a representative electron diffraction pattern recorded by directing the electron beam perpendicular to the $\{100\}$ facets of an individual nanocube and confirms that the Pt nanoparticles are single crystals. Based on a previous report, we believe that the nanocubes are formed as a result of fast growth along the $\{111\}$ directions, and that the surfaces of the final nanocubes correspond to $\{100\}$ planes [26].

The above results show that the $1 \mathrm{~mol} / \mathrm{L} \mathrm{HCl}$ and $1 \mathrm{~mol} / \mathrm{L} \mathrm{H}_{2} \mathrm{SO}_{4}$ in the aqueous solution both play distinct roles in the formation of the Pt nanostructures. In the absence of $\mathrm{HCl}$, with an aqueous solution of $2 \mathrm{~mol} / \mathrm{L} \mathrm{H}_{2} \mathrm{PtCl}_{6}+1 \mathrm{~mol} / \mathrm{L} \mathrm{H}_{2} \mathrm{SO}_{4}, \mathrm{SO}_{4}^{2-}$ ions from $\mathrm{H}_{2} \mathrm{SO}_{4}$ had a negligible effect on the synthesis of the $\mathrm{Pt}$ nanocubes because the concentration of $\mathrm{H}_{2} \mathrm{SO}_{4}$ was lower than the concentration of $\mathrm{H}_{2} \mathrm{PtCl}_{6}$. Figure 4(c) shows a typical SEM image of the truncated Pt nanocubes at $t=20 \mathrm{~min}$, which consist of a mixture of small $\mathrm{Pt}$ cubes and rods. This observation implies that $\mathrm{H}_{2} \mathrm{SO}_{4}$ alone is able to induce the etching and dissolution of seeds and thus, direct the product towards truncated single crystal nanocubes. The truncated shape may arise because there are sufficient $\mathrm{H}^{+}$and $\mathrm{Cl}^{-}$ions for etching and dissolution (as shown in Fig. S-7(a) in the $\mathrm{ESM})$. On the other hand, when $\mathrm{HCl}$ was added to the aqueous solution of $2 \mathrm{~mol} / \mathrm{L} \mathrm{H}_{2} \mathrm{PtCl}_{6}+1 \mathrm{~mol} / \mathrm{L} \mathrm{H}_{2} \mathrm{SO}_{4}$, $\mathrm{Cl}^{-}$ions from $\mathrm{HCl}$ should have a marked effect on the synthesis of the perfect Pt nanocubes because they can reduce the surface energies of the $\{100\}$ facets of the seeds by binding strongly to them, thus, leading to the formation of perfect nanocubes. The presence of $\mathrm{Cl}^{-}$ions in the aqueous solution stabilizes the single crystal and therefore $\mathrm{Cl}^{-}$ions also can prevent the 
nanocubes from aggregating or sedimentation, by providing electrostatic repulsion forces between the $\mathrm{Pt}$ nanocubes (as shown in Fig. S-7(b) in the ESM) [27].

To compare the kinetic effects and the effect of the FS wafer on the geometrical structure, Pt nanoparticles were also deposited on a single silicon substrate by electroless deposition. After etching the outer $\mathrm{SiO}_{2}$ layer, a single silicon substrate was dipped for $6 \mathrm{~h}$ in a solution of $1 \mathrm{~mol} / \mathrm{L} \mathrm{HCl}+2 \mathrm{~mol} / \mathrm{L} \mathrm{H}_{2} \mathrm{PtCl}_{6}+1 \mathrm{~mol} / \mathrm{L}$ $\mathrm{H}_{2} \mathrm{SO}_{4}$ which had been vigorously stirred for $5 \mathrm{~h}$ at room temperature. A long deposition time was employed so that the kinetic factor has negligible effect on the synthesis and growth of Pt nanoparticles. Figure S-8(a)

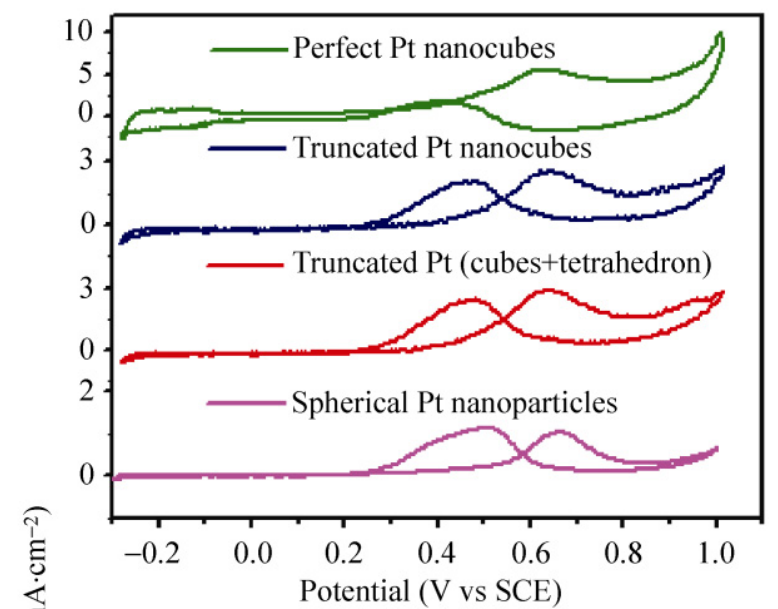

(a)

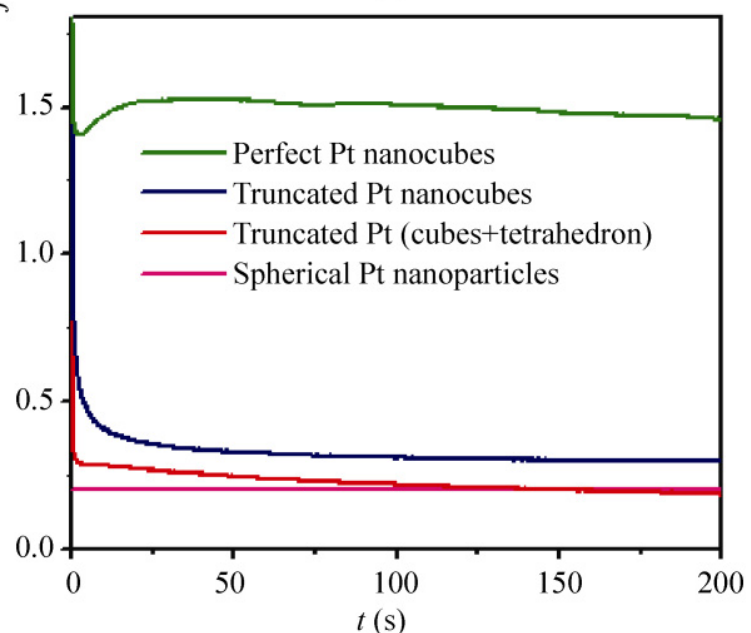

(c) (in the ESM) shows that the resulting Pt nanoparticles were spherical. This might be due to the low charge density on the single silicon wafer compared to that on a pair of FS wafers in very close proximity in aqueous solution. The charges were developed on the silicon surface by etching in HF aqueous solution.

\subsection{Catalytic activity tests}

Finally, the size-, shape-, and structure-controlled synthesis of Pt nanoparticles allows us to study surfacedependent properties such as catalytic activity. Figures 6(a) and 6(b) show cyclic voltammograms for methanol and ethanol oxidation on the perfect $\mathrm{Pt}$

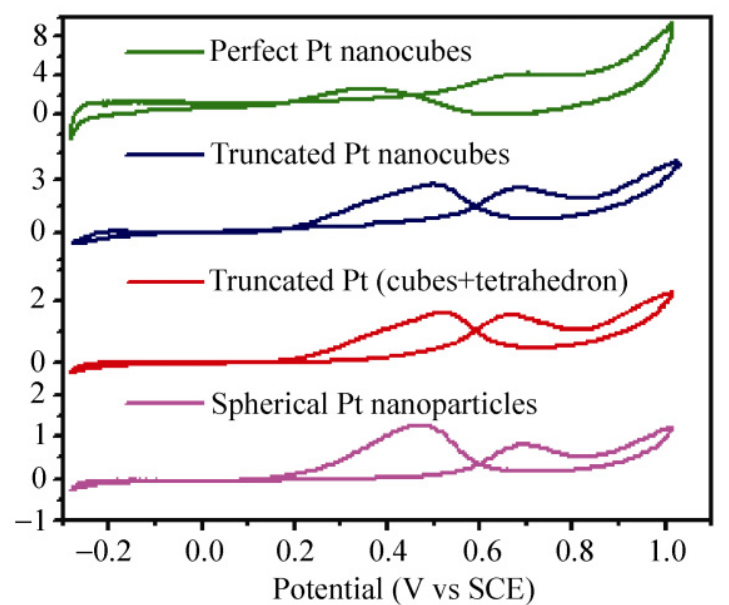

(b)

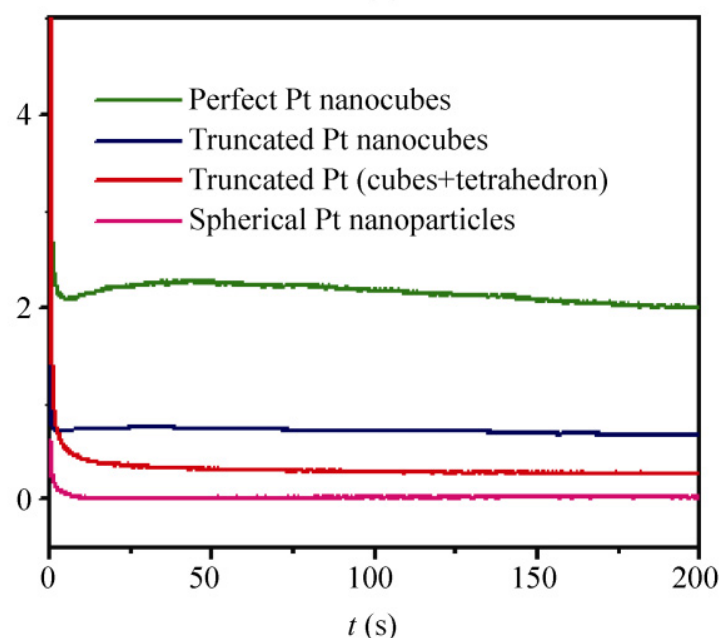

(d)

Figure 6 Comparison of the catalytic activity and stability of the Pt nanoshapes. Cyclic voltammograms for ( I ) perfect Pt nanocubes, (II) truncated Pt nanocubes, (III) truncated Pt (cubes + tetrahedra), and (IV) spherical Pt nanoparticles obtained at a scan rate of $25 \mathrm{mVs}{ }^{-1}$ in (a) $1 \mathrm{~mol} / \mathrm{L} \mathrm{H}_{2} \mathrm{SO}_{4}+1 \mathrm{~mol} / \mathrm{L}$ methanol and (b) $1 \mathrm{~mol} / \mathrm{L} \mathrm{H}_{2} \mathrm{SO}_{4}+1 \mathrm{~mol} / \mathrm{L}$ ethanol; chronoamperometric curves for (I) perfect Pt nanocubes, ( II ) truncated Pt nanocubes, (III) truncated Pt (cubes + tetrahedra), and (IV) spherical Pt nanoparticles recorded at $\sim 0.40 \mathrm{~V}$ in oxygen-free (c) $1 \mathrm{~mol} / \mathrm{L} \mathrm{H}_{2} \mathrm{SO}_{4}+1 \mathrm{~mol} / \mathrm{L}$ methanol and (d) $1 \mathrm{~mol} / \mathrm{L} \mathrm{H}_{2} \mathrm{SO}_{4}+1 \mathrm{~mol} / \mathrm{L}$ ethanol. The results demonstrate that the perfect Pt nanocube electrode showed excellent catalytic activity and stability for the oxidation of methanol and ethanol 
nanocubes (Fig. 5(b)), truncated Pt nanocubes (Fig. 4(b)), truncated $\mathrm{Pt}$ (cubes + tetrahedra) (Fig. 3(c)), and spherical Pt nanoparticles (Fig. S-9 in the ESM) at room temperature. As shown in Figs. 6(a) and 6(b), the onset potential for methanol and ethanol electrooxidation with the perfect $\mathrm{Pt}$ nanocubes was lower than that for the truncated $\mathrm{Pt}$ nanocubes, truncated $\mathrm{Pt}$ (cubes + tetrahedra), or spherical $\mathrm{Pt}$ nanoparticles, indicative of faster electrode kinetics [28]. In addition, the perfect Pt nanocubes showed a peak current density higher than that for the truncated $\mathrm{Pt}$ nanocubes, truncated $\mathrm{Pt}$ (cubes + tetrahedra), or spherical Pt nanoparticles. The current densities were calculated by normalizing to the actual Pt area.

Furthermore, a chronoamperometry study was carried out to determine the stability of electrocatalytic activity towards methanol oxidation-reduction and ethanol oxidation-reduction. Figures 6(c) and 6(d) show chronoamperograms of the four electrodes, which were obtained by measuring the steady-state reaction current density at an electrode potential of $\sim 0.4 \mathrm{~V}$. After the polarization for $200 \mathrm{~s}$, the current density in methanol electrooxidation for the perfect $\mathrm{Pt}$ nanocubes, the truncated Pt nanocubes, the truncated Pt (cubes + tetrahedra), and the spherical Pt nanoparticles were $\sim 1.45, \sim 0.29, \sim 0.18$, and $\sim 0.16 \mathrm{~mA} / \mathrm{cm}^{2}$ respectively. A similar pattern was also observed for the current densities in ethanol electrooxidation, i.e., highest in the case of the perfect Pt nanocubes $\left(\sim 2.01 \mathrm{~mA} / \mathrm{cm}^{2}\right)$, moderate in truncated $\mathrm{Pt}$ nanocubes $\left(\sim 0.66 \mathrm{~mA} / \mathrm{cm}^{2}\right)$, and lowest in truncated $\mathrm{Pt}(\sim 0.27)$ and spherical $\mathrm{Pt}$ nanoparticles $\left(\sim 0.016 \mathrm{~mA} / \mathrm{cm}^{2}\right)$. These results show that the perfect $\mathrm{Pt}$ nanocubes have much higher activity than the other nanostructures, with a steady-state current that is over five times, eight times, and nine times higher than those of the truncated Pt nanocubes, truncated $\mathrm{Pt}$ (cubes + tetrahedra), and spherical $\mathrm{Pt}$ nanoparticles, respectively. The perfect $\mathrm{Pt}$ nanocubes exhibit both good stability and high electrocatalytic activity towards oxidation of methanol and ethanol. The enhanced electrocatalytic property of the perfect $\mathrm{Pt}$ nanocubes can be attributed to the exposed $\mathrm{Pt}\{100\}$ faces of the single crystals. $\mathrm{CO}$ oxidation activity is known to be higher on $\mathrm{Pt}\{100\}$ faces than on $\mathrm{Pt}\{111\}$ and $\mathrm{Pt}\{110\}$ and, consequently, the CO poisoning effect on $\mathrm{Pt}\{100\}$ faces is much lower [29]. In addition, the edges of stepped $\{100\}$ faces can induce cleavage of
$\mathrm{C}-\mathrm{C}$ or $\mathrm{C}-\mathrm{H}$ bonds in $\mathrm{CH}_{3} \mathrm{OH}$ and $\mathrm{CH}_{3} \mathrm{CH}_{2} \mathrm{OH}$ with much higher efficiency than those in truncated $\mathrm{Pt}$ nanocubes, truncated $\mathrm{Pt}$ (cubes + tetrahedra), and spherical Pt nanoparticles [30]. Consequently, our facile synthesis of perfect $\mathrm{Pt}$ nanocubes will have a great impact on the development of high-performance liquid-feed fuel cells.

\section{Conclusions}

We have demonstrated, for the first time, a simple and efficient method for the synthesis and growth of well-dispersed perfect platinum (Pt) nanocubes, employing a pair of low-resistivity FS wafers at room temperature in the absence of surfactants, additives, capping materials, and reducing agents. The perfect Pt nanocubes deposited on the FS wafers exhibited a much higher catalytic activity and stability for methanol and ethanol oxidation than truncated $\mathrm{Pt}$ nanocubes, truncated $\mathrm{Pt}$ (cubes + tetrahedra) or spherical Pt nanoparticles. Moreover, we found that the morphology and dimensions of the $\mathrm{Pt}$ nanocubes were greatly influenced by the homogeneity of the aqueous precursor solution, dipping time and charge density. For example, with increasing homogeneity of the solution, $>98 \%$ of the cubes were formed with sharp edges. Prolonged dipping times of the FS substrate resulted in the formation of both cubes and nanorods. High-charge density accelerates the deposition of $\mathrm{Pt}$ nanocubes, as is evident by comparing the FS wafer with a single silicon wafer. We believe that this new and simple method will open a door to the synthesis of other metals (for instance silver, gold, and copper) with well-controlled shape, size, and facets for optical, electrical, thermal, magnetic, and catalytic applications. Further work is still underway to synthesize such other metal nanostructures by the same process. Besides the shape-controlled synthesis of other metals, this facile synthesis process also allows a deeper understanding of the fundamental aspects of shapecontrolled nanoparticle formation.

\section{Acknowledgements}

The authors thank Prof. Fuming Pan for availing the necessary laboratory facilities, chemicals, and reagents.

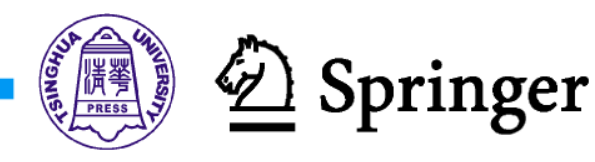


Electronic Supplementary Material: Supplementary material (detailed experimental procedures, SEM image of Pt nanostructures, SAED pattern of truncated $\mathrm{Pt}$ nanocubes, histograms of particle size distributions, XPS spectrum of the perfect Pt nanocubes, schematic representation of active roles played by $\mathrm{H}^{+}$and $\mathrm{Cl}^{-}$ ions, SEM images of the Si after electroless deposition, and SEM, HRTEM, SAED of the electrodeposited Pt nanospheres) is available in the online version of this article at http://dx.doi.org/10.1007/s12274-011-0110-4.

\section{References}

[1] Elmalem, E.; Saunders, A. E.; Costi, R.; Salant, A; Banin, U. Growth of photocatalytic CdSe-Pt nanorods and nanonets. Adv. Mater. 2008, 20, 4312-4317.

[2] Sun, L.; Ca, D. V.; Cox, J. A. Electrocatalysis of the hydrogen evolution reaction by nanocomposites of poly(amidoamine)encapsulated platinum nanoparticles and phosphotungstic acid. J. Solid State Electrochem. 2005, 9, 816-822.

[3] Tiwari, J. N.; Chen, T. M.; Pan, F. M; Lin, K. L. Ordered silicon nanocones as a highly efficient platinum catalyst support for direct methanol fuel cells. J. Power Sources 2008, 182, 510-514.

[4] Tiwari, J. N.; Pan, F. M.; Tiwari, R. N.; Nandi, S. K. Facile synthesis of continuous $\mathrm{Pt}$ island networks and their electrochemical properties for methanol electrooxidation. Chem. Commun. 2008, 6516-6518.

[5] Tiwari, J. N.; Pan, F. M.; Lin, K. L. Facile approach to the synthesis of 3D platinum nanoflowers and their electrochemical characteristics. New J. Chem. 2009, 33, 1482-1485.

[6] Tiwari, J. N.; Tiwari, R. N.; Lin, K. L. Synthesis of Pt nanopetals on highly ordered silicon nanocones for enhanced methanol electrooxidation activity. ACS Appl. Mater. Interfaces 2010, 2, 2231-2237.

[7] Tian, N.; Zhou, Z. Y.; Sun, S. G.; Cui, L.; Ren, B.; Tian, Z. Q. Electrochemical preparation of platinum nanothorn assemblies with high surface enhanced Raman scattering activity. Chem. Commun. 2006, 4090-4092.

[8] Toshima, N.; Shiraishi, Y.; Teranishi, T.; Miyake, M.; Tominaga, T.; Watanabe, H.; Brijoux, W.; Bonnemann, H.; Schmid, G. Various ligand-stabilized metal nanoclusters as homogeneous and heterogeneous catalysts in the liquid phase. Appl. Organomet. Chem. 2001, 15, 178-196.

[9] Chen, J.; Herricks, T.; Xia, Y. Polyol synthesis of platinum nanostructures: Control of morphology through the mani- pulation of reduction kinetics. Angew. Chem. Int. Ed. 2005, 44, 2589-2592.

[10] Tian, N.; Zhou, Z. Y.; Sun, S. G.; Ding, Y.; Wang, Z. L. Synthesis of tetrahexahedral platinum nanocrystals with highindex facets and high electro-oxidation activity. Science 2007, 316, 732-735.

[11] Sun, Y; Xia, Y. Shape-controlled synthesis of gold and silver nanoparticles. Science 2002, 298, 2176-2179.

[12] Lee, H.; Habas, S. E.; Kweskin, S.; Butcher, D.; Somorjai, G. A.; Yang, P. D. Morphological control of catalytically active platinum nanocrystals. Angew. Chem. Int. Ed. 2006, $45,7824-7828$.

[13] Ahmadi, T. S.; Wang, Z. L.; Green, T. C.; Henglein, A.; El-Sayed, M. A. Shape-controlled synthesis of colloidal platinum nanoparticles. Science 1996, 271, 1924-1926.

[14] Wang, C.; Hideo, D.; Lee, Y.; Kim, J.; Sun, S. Synthesis of monodisperse Pt nanocubes and their enhanced catalysis for oxygen reduction. J. Am. Chem. Soc. 2007, 129, 6974-6975.

[15] Chen, J. Y.; Herricks, T.; Geissler, M.; Xia, Y. N. Singlecrystal nanowires of platinum can be synthesized by controlling the reaction rate of a polyol process. J. Am. Chem. Soc. 2004, 126, 10854-10855.

[16] Kijima, T.; Yoshimura, T.; Uota, M.; Ikeda, T.; Fujikawa, D.; Mouri, S.; Uoyama, S. Noble-metal nanotubes (Pt, Pd, Ag) from lyotropic mixed-surfactant liquid-crystal templates. Angew. Chem. Int. Ed. 2004, 43, 228-232.

[17] Teng, X. W.; Yang, H. Synthesis of platinum multipods: An induced anisotropic growth. Nano Lett. 2005, 5, 885-891.

[18] Ullah, M. H.; Chung, W. S.; Kim, I.; Ha, C. S. pH-Selective synthesis of monodisperse nanoparticles and 3D dendritic nanoclusters of CTAB-stabilized platinum for electrocatalytic $\mathrm{O}_{2}$ reduction. Small 2006, 2, 870-873.

[19] Balint, I.; Miyazaki, A.; Aika, K. NO reduction by $\mathrm{CH}_{4}$ over well-structured $\mathrm{Pt}$ nanocrystals supported on $\gamma-\mathrm{Al}_{2} \mathrm{O}_{3}$. Appl. Catal. B 2002, 37, 217-229.

[20] Vidal-Iglesias, F. J.; Solla-Gullon, J.; Rodriguez, P.; Herrero, E.; Montiel, V.; Feliu, J. M.; Aldaz, A. Shape-dependent electrocatalysis: Ammonia oxidation on platinum nanoparticles with preferential (100) surfaces. Electrochem. Commun. 2004, 6, 1080-1084.

[21] Inaba, M.; Ando, M.; Hatanaka, A.; Nomoto, A.; Matsuzawa, K.; Tasaka, A.; Kinumoto, T.; Iriyama, Y.; Ogumi, Z. Controlled growth and shape formation of platinum nanoparticles and their electrochemical properties. Electrochim. Acta 2006, 52, 1632-1638.

[22] Ye, H. C.; Crooks, R. M. Electrocatalytic $\mathrm{O}_{2}$ reduction at glassy 
carbon electrodes modified with dendrimer-encapsulated $\mathrm{Pt}$ nanoparticles. J. Am. Chem. Soc. 2005, 127, 4930-4934.

[23] Song, H.; Kim, F.; Connor, S.; Somorjai, G. A.; Yang, P. Pt nanocrystals: Shape control and Langmuir-Blodgett monolayer formation. J. Phys. Chem. B 2005, 109, 188-193.

[24] Grass, M. E.; Yue, Y.; Habas, S. E.; Rioux, R. M.; Teall, C. I.; Yang P.; Somorjai, G. A. Silver ion mediated shape control of platinum nanoparticles: Removal of silver by selective etching leads to increased catalytic activity. J. Phys. Chem. C 2008, 112, 4797-4804.

[25] Yang, W.; Wang, X.; Yang, F.; Yang, C.; Yang, X. Carbon nanotubes decorated with $\mathrm{Pt}$ nanocubes by a noncovalent functionalization method and their role in oxygen reduction. Adv. Mater. 2008, 20, 2579-2587.

[26] Kim, D.; Lee, N.; Park, M.; Kim, B. H.; An, K.; Hyeon, T.
Synthesis of uniform ferrimagnetic magnetite nanocubes. $J$. Am. Chem. Soc. 2009, 131, 454-455.

[27] Kim, M. H.; Lim, B.; Lee, E. P.; Xia, Y. Polyol synthesis of $\mathrm{Cu}_{2} \mathrm{O}$ nanoparticles: Use of chloride to promote the formation of a cubic morphology. J. Mater. Chem. 2008, 18, 4069-4073.

[28] Tripković, A. V.; Štrbac, S.; Popović, K. D. Effect of temperature on the methanol oxidation at supported Pt and $\mathrm{PtRu}$ catalysts in alkaline solution. Electrochem. Commun. 2003, 5, 484-490.

[29] Markovic, N. M.; Ross Jr, P. N. Surface science studies of model fuel cell electrocatalysts. Surf. Sci. Rep. 2002, 45, 117-229.

[30] Han, S. B.; Song, Y. J.; Lee, J. M.; Kim, J. Y.; Park, K. W. Platinum nanocube catalysts for methanol and ethanol electrooxidation. Electrochem. Commun. 2008, 10, 1044-1047. 